\section{The inverse groups?}

Lee and colleagues (Improving the quality of care for infants: a cluster randomized controlled trial, Aug. 10 online) have presented an intriguing evaluation of 2 QI interventions in their NICUs. The pulmonary group implemented only $23 \%$ of their own selected potentially useful practices, but with good effect. The infection group showed no pulmonary change. Collection and presentation of the NI group's pulmonary practices would have enhanced the reader's ability to judge which of the implemented practices were associated with change. I would encourage the investigators to make these data available.

David D. Wirtschafter, MD

Valley Village, Calif. USA

For the full letter go to: www.cmaj.ca/cgi/eletters /cmaj.081727v1

DOI:10.1503/cmaj.109-2016

\section{Dying for knowledge}

Re: Defining knowledge translation, Aug. 4

At every stage in the knowledge cycle, there are barriers and challenges that are consistently greater in developing countries. This means that people in developing countries are dying for lack of knowledge. To explore these issues in depth, I would like to invite the authors and $C M A J$ readers to join Healthcare Information For All by 2015 (HIFA2015), more than 2500 health professionals, researchers and publishers, supported by the British Medical Association, WHO and others.

\section{Dr Neil Pakenham-Walsh MB BS \\ Charlbury, UK}

For the full letter go to: www.cmaj.ca/cgi/eletters /181/3-4/165\#150685

DOI:10.1503/cmaj.109-2011

\section{Fear of statins?}

Congratulations CMAJ on adding to the fear of myopathy with statin therapy based on the article by Mohaupt et al (July 7). Nowhere is it mentioned how frequent statin myopathy might be. And in the groups with statin myopathy, most were concurrently taking drugs known either to cause myopathy or increase the risk with statin therapy. So, what comes out in the popular press: "Cholesterol pills can be a pain"; "Cholesterol drugs linked to long-lasting muscle injury". Why didn't the reviewers and editors of CMAJ ask to see more results on patients with myopathy just on statins? For now, patients will be stopping medications without physician supervision or questioning their physicians' judgment and recommendations.

\section{David Miller MD FRCPC Cert Endo \\ Vancouver Island Health Authority Victoria, BC}

For the full letter go to: www.cmaj.ca/cgi/eletters /181/1-2/E11\#140400

DOI:10.1503/cmaj. 109-2013

\section{Is the tail wagging the dog?}

Re: The 10 000-hour rule and residency training, Salon, June 9

As a relatively recent graduate, I would respectfully disagree with this article. Dr. Omahen presumes that the primary objective of health care delivery is resident education. In fact, the primary goal is - and should always be - patient care. When I was a student, I was told by a more senior trainee: "Remember, at the end of the day, you are ultimately responsible for your own education." I took this advice to heart and I would strongly advise current trainees to do the same.

\section{Raj S. Padwa}

University of Alberta

For the full letter go to: www.cmaj.ca/cgi/eletters /180/12/1272\#163379

DOI:10.1503/cmaj.109-2012

\section{Climate change}

Dr. Mehta's article (Salon, May 26) opens with the statement: "Most people, except perhaps a few diehard oil executives, have accepted that climate change is largely due to human activities." Four hundred years ago, "most people" accepted that the earth was flat and that the sun revolved around it. I am no authority on climate change but I do believe that the question is by no means as settled as the author assumes. I would strongly urge anyone who has doubts to read Lawrence Solomon's book The Deniers. Solomon presents opposing views of various important scientists.

\section{Martin Gough MB BCh FRCS(C) \\ Victoria, BC}

For the full letter go to: www.cmaj.ca/cgi/eletters /180/11/1176\#137237

DOI:10.1503/cmaj.109-2001 